\title{
Solo-cimento autoadensável com incorporação de areia de resíduos de construção civil para aplicação em sistema de vedação vertical
}

\author{
Self-compacting soil-cement with incorporation of sand \\ from construction waste for application in a vertical \\ panel system
}

\section{Fernanda Cavatti Simioni \\ Ivan Julio Apolonio Callejas \\ Luciane Cleonice Durante \\ Bruna Guimarães de Souza}

${ }^{1}$ Fernanda Cavatti Simioni ${ }^{1}$ Faculdade de Ciências Biomédicas de

Cacoal Cacoal - RO - Brasil

${ }^{2}$ Ivan Julio Apolonio Callejas 2Universidade Federal de Mato Grosso Cuiabá - MT - Brasil

${ }^{3}$ Luciane Cleonice Durante ${ }^{3}$ Universidade Federal de Mato Grosso Cuiabá - MT - Brasil

${ }^{4}$ Bruna Guimarães de Souza ${ }^{4}$ Universidade Federal de Mato Grosso Cuiabá - MT - Brasil

Recebido em 31/01/20 Aceito em 15/04/20

\section{Resumo}

$\mathbf{T}$ em-se por objetivo analisar a influência da incorporação de areia de resíduos de construção civil (RCC) no comportamento físico e mecânico de misturas de solo-cimento autoadensável (SCAA), visando sua aplicação em sistema de vedação vertical monolítico. O método consiste em realização dos ensaios laboratoriais, considerando um traço inicial de cimento-solo na proporção 1:5, e mais quatro traços, em que se substitui o solo por areia de RCC em intervalos de $25 \%$ até $100 \%$, em massa. No estado fresco, conduziram-se ensaios de espalhamento (faixa de $660 \mathrm{~mm}$ a $750 \mathrm{~mm}$ ), densidade da massa e teor de ar incorporado e, no estado endurecido, ensaios de resistência à compressão simples, absorção de água e índice de vazios. Observou-se melhora na trabalhabilidade e na vazão mássica nas misturas híbridas, obtendo-se maiores resistências mecânicas nos traços com incorporação de $25 \%$ e $50 \%$ de areia de RCC, indicando um possível intervalo de dosagem ótima. Além disso, a incorporação de areia de RCC diminuiu a absorção de água, com valores abaixo de $20 \%$ em todos os traços híbridos. Conclui-se que a utilização de areia de RCC em misturas de SCAA apresenta potencial para aplicação de sistema de vedação vertical monolítico.

Palavras-chave: Solo-cimento. Vedação vertical. Areia reciclada.

\section{Abstract}

The aim of this study is to analyse the influence of the incorporation of construction waste $(C W)$ sand on the physical and mechanical behaviour of selfcompacting soil-cement (SCSC) mixes, aiming at its application in a monolithic vertical panel system. The research method consists of conducting laboratory tests, considering an initial proportion of cement-soil with a 1:5 ratio, and four additional mixes, in which soil was replaced by CCW sand at intervals of $25 \%$ up to $100 \%$, in mass. In the fresh state, tests were conducted to determine fluid consistency (ranging from 660 to $750 \mathrm{~mm}$ ), mass density and the air content incorporated in the mixes. In the hardened state, simple compressive strength, water absorption and voids content tests were undertaken. Improvements in the workability and mass flow rate were observed in the hybrid mixes, and higher mechanical strengths were obtained with the incorporation of $25 \%$ and $50 \%$ of $C C W$ sand, indicating an ideal dosage within this interval. In addition, the incorporation of CCW sand reduced water absorption, with values below $20 \%$ in all hybrid mixes. The study concluded that the use of CCW sand in SCSC mixes has the potential to be applied in the Vertical Monolithic Panel System.

Keywords: Soil-cement. Verrical panel system. Recycled sand. 


\section{Introdução}

O setor da construção civil é uma das atividades econômicas que mais utiliza matérias-primas virgens em seus processos, promovendo significativos impactos ambientais negativos resultantes do consumo e descarte de bens naturais ou manufaturados, da ampla ocupação e modificação da paisagem, bem como da degradação e poluição ambiental (SAKR; SHERIF; EL-HAGGAR, 2010). À medida que essas matériasprimas virgens se movem como insumos na cadeia produtiva do setor, nota-se considerável geração de resíduos. Quando estes não são gerenciados de forma correta e dispostos inadequadamente na natureza, continuam causando impactos ambientais negativos, tais como degradação do solo, comprometimento dos corpos hídricos superficiais e lençóis freáticos, obstrução dos sistemas de drenagem, intensificação de enchentes, degradação da paisagem urbana e ocupação de vias e logradouros públicos (FUNDAÇÃO..., 2010; AGOPYAN; JOHN, 2011; DELONGUI et al., 2011; LU; TAM, 2013; YEHEYIS et al., 2013).

Como medida de mitigação, tem-se o reaproveitamento dos resíduos oriundos da construção civil, denominados RCC, que reduz a extração de recursos naturais e a geração de materiais para descarte. Na atualidade, principalmente nos países em desenvolvimento, os RCC têm sido descartados incorretamente, o que se torna um obstáculo ao seu reaproveitamento, além de promover riscos à saúde humana e ao meio ambiente (RIBEIRO; MOURA; PIROTE, 2016). Como os maiores impactos ambientais e econômicos pela disposição incorreta de resíduos da construção civil são gerados nas fases de construção e demolição, o desenvolvimento de tecnologias construtivas de reaproveitamento são de primordial importância para promoção da sustentabilidade no setor (PASSUELLO et al., 2014).

Diante disso, vislumbra-se a possiblidade de incorporação de RCC nas misturas de solo-cimento autoadensável (SCAA). O solo-cimento, conforme a NBR 12253 (ABNT, 2012c), é definido como o resultado da mistura do solo, cimento e água, em proporções definidas por dosagens específicas para cada caso de aplicação. Na mistura, o cimento visa estabilizar o solo, e a água hidratar o cimento e favorecer a compactação. O solo-cimento autoadensável (SCAA) possui maior teor de cimento em relação ao solocimento convencional, recebe maior quantidade de água e é aditivado com plastificantes para aumentar sua trabalhabilidade, e pode, ainda, receber adição de finos, que aprimoram suas características tanto no estado fresco como no endurecido (LLAJARUNA, 2017).

Esse tema tem sido pesquisado nos últimos anos, com enfoque em dosagens de SCAA (BERTÉ, 2012; MILANI; BARBOZA, 2016; FERNANDES, 2017), em adição de resíduos como fibras curtas de sisal (MARTINS, 2014), em incorporação de resíduos de concreto (BEZERRA; LAFAYETTE, 2016), de cinza de casca de arroz no estado fresco e endurecido (CLAVERIE, 2015), de microfibras de polipropileno (SOUZA; PAZ; MILANI, 2016) e, ainda, de pó de mármore juntamente com resíduo de construção (LLAJARUNA, 2017). É importante destacar que essas pesquisas tiveram caráter exploratório, avaliando o desempenho das misturas para potencial aplicação em paredes monolíticas e blocos, e que em nenhum deles investigou-se a incorporação de areia de RCC.

Diante disso, o objetivo deste estudo é analisar a influência da incorporação de areia de resíduos de construção civil (RCC) no comportamento físico e mecânico de misturas de solo-cimento autoadensável (SCAA), visando à aplicação em sistema de vedação vertical monolítico.

Como contribuição do estudo, além de preencher a lacuna no conhecimento sobre o tema acerca da incorporação de areia de RCC, o sistema de vedação vertical pesquisado é ambientalmente mais sustentável, por envolver reciclagem de materiais e ser produzido a partir de solo cru, que requer menor energia incorporada quando comparado aos sistemas tradicionais (GRAF; TAVARES, 2010).

\section{Referencial teórico}

A utilização de solo estabilizado com cimento ou cal vem sendo amplamente pesquisada como alternativa aos tradicionais insumos utilizados na construção civil. A maioria dessas pesquisas volta-se para a confecção de tijolos ou blocos, por meio de técnicas de prensagem ou compactação do material, para fins de vedação (MILANI; BARBOZA, 2016).

Estudos recentes apontam para a utilização do solo-cimento no estado plástico, com consistência similar à de argamassa e moldado em fôrma similar à de concreto autoadensável. Esse material é denominado solocimento autoadensável (SCAA), que em virtude de seu estado plástico permite maior rapidez na produção e aplicação, uma vez que seu adensamento ocorre por meio do seu peso próprio (BERTÉ; ALCÂNTARA, 2013; MILANI; BARBOZA, 2016; FERNANDES, 2017). Em função dessas características, o SCAA pode 
ser utilizado para a produção de fechamentos verticais formados por elemento único e contínuo, conformando um sistema de vedação vertical monolítico, com ou sem função estrutural.

Pela ótica da sustentabilidade, pesquisas com solo-cimento convencional ou autoadensável visam minimizar impactos ambientais e consumo de energia, com incorporação de materiais alternativos aos tradicionalmente usados, com o desenvolvimento de novos compósitos para o setor da construção civil. As pesquisas nessa área que focam no SCAA analisam o desempenho físico e mecânico das misturas com incorporação de resíduos sólidos (agregados) poliméricos, minerais e vegetais.

Martins (2014) realizou a caracterização física e mecânica dos compósitos de solo-cimento reforçados com fibras curtas de sisal em teores de $0,5 \%, 1,0 \%$ e $1,5 \%$, em relação ao peso seco do solo, com comprimentos de $20 \mathrm{~mm}$ e $50 \mathrm{~mm}$. A incorporação de fibras possibilitou o aumento da resistência à compressão e tração do material em relação ao traço de referência, melhoria nas propriedades pós-fissuração, além de proporcionar a redução da retração por secagem. Os valores encontrados para absorção de água aos 28 dias de cura foram inferiores aos da mistura de referência. Concluiu-se pela potencialidade do uso dos referidos compósitos na construção civil, visando à produção de painéis monolíticos de alvenaria de vedação.

Claverie (2015) pesquisou o comportamento do SCAA com adição de cinza de casca de arroz (CCA) no estado fresco e endurecido. Foram realizadas 18 dosagens variando a quantidade de cimento $(26,7 \%, 30 \%$ e $33,3 \%)$, mantendo-se constantes a relação água/materiais em massa seca (30\%) e a quantidade de aditivo em relação ao solo+cimento $(0,4 \%)$. No estado fresco, para o maior teor de cimento adotado, a mistura com adição de cinza de casca de arroz apresentou diminuição da trabalhabilidade. No estado endurecido, observou-se a diminuição da absorção de água de $21 \%$ no traço de referência para $15 \%$ no traço das misturas híbridas, bem como a elevação da resistência mecânica à compressão em todas as misturas.

Bezerra e Lafayette (2016) pesquisaram misturas de solo-cimento compostas por solo natural e com incorporação, em relação à massa de solo, de $25 \%$ (agregados miúdos e graúdos até 4,8 mm), 50\% e 75\% de RCC. Para cada uma das composições, o teor de cimento foi de $8 \%$ em relação à massa da mistura soloresíduo. Os resultados indicaram que todas as composições atenderam aos requisitos normativos quanto às propriedades tecnológicas para a produção de blocos, atingindo resistência mecânica à compressão superior a 2,1 MPa.

Souza, Paz e Milani (2016) adotaram como ponto de partida misturas de solo-cimento unitárias 1:5 e 1:4 (cimento:solo, em massa) sem e com adição de microfibras de polipropileno. Fixou-se o percentual de 1,2\% de aditivo em relação à massa do cimento para a elaboração das misturas. Variou-se a quantidade de água da mistura fresca até que se atingisse uma abertura entre $660 \mathrm{~mm}$ e $750 \mathrm{~mm}$ no ensaio de espalhamento (slump flow test). Tomando-se como referência a resistência mínima indicada para paredes autoportantes de edificações, bem como o consumo mínimo de cimento, optou-se pela mistura 1:5 com e sem adição de microfibras de polipropileno para a confecção dos painéis de paredes monolíticas de SCAA. O estudo apontou a viabilidade técnica de seu uso em paredes monolíticas moldadas in loco, visto que, no estado fresco, a mistura se apresentou fluida, homogênea, sem segregação, e que, no estado endurecido, alcançou resistências mecânicas médias entre 1,80 MPa e 7,16 MPa, adequadas à finalidade de aplicação.

Llajaruna (2017) produziu oito misturas de solo-cimento autoadensável com adição de pó de mármore e resíduo de construção visando à fabricação de tijolos. Nos ensaios preliminares adotou as seguintes dosagens: $31 \%$ de água/materiais secos, 0,9\% de aditivo/solo+cimento, 33,3\% de cimento/solo, pó de mármore e resíduo da construção civil variando entre $0 \%$ e $40 \%$. No estado fresco, realizou ensaios de espalhamento, do funil e segregação e, no estado endurecido, de resistência à compressão axial aos $7,14 \mathrm{e}$ 28 dias e absorção de água. Observou que, no estado fresco, o teor de pó de mármore e o resíduo de construção contribuem para a trabalhabilidade e vazão mássica, bem como evitam a segregação. No estado endurecido, com os teores de $20 \%$ de pó de mármore e $10 \%$ de resíduo de construção, a mistura obteve melhor desempenho mecânico, com $8,20 \mathrm{MPa}$, quando comparada às demais dosagens. A resistência à compressão e absorção de água atenderam às exigências normativas.

França et al. (2018) realizaram um estudo de blocos de solo-cimento com resíduos de calcário para compreender a durabilidade do material. Os traços eram compostos por $10 \%$ de cimento com incorporação de calcário em teores de $10 \%$ a $50 \%$. Observou-se elevação da resistência à compressão simples e redução da absorção de água para teores de incorporação de resíduos de calcário até $30 \%$, a partir do qual a resistência sofreu decréscimo e a absorção de água se elevou. Conclui-se pela viabilidade técnica da utilização de resíduos de calcário para produção de blocos de solo-cimento. 
Spósito et al. (2018) avaliaram a viabilidade da utilização do resíduo de PET na produção de SCAA. No estado fresco, avaliou-se a trabalhabilidade, viscosidade, a presença de segregação e exsudação a partir de ensaios de espalhamento, funil e segregação por peneiramento. No estado endurecido, conduziram-se ensaios de resistência à compressão axial, resistência à tração por compressão diametral e de absorção, a partir de corpos de prova cilíndricos $5 \mathrm{~cm}$ x $10 \mathrm{~cm}$. Os resultados no estado fresco não foram satisfatórios, observando-se a presença de exsudação nas misturas com $5 \%$ e $10 \%$ de substituição de resíduo de PET e redução da resistência à compressão axial em $21,50 \%$ e $12,70 \%$, respectivamente. Observou-se, no entanto, o aspecto positivo de diminuição do teor de absorção de água.

\section{Materiais e métodos}

\section{Materiais}

\section{Solo}

A amostra de solo utilizada na pesquisa é oriunda de processo de escavação de obra civil, previamente identificada como latossolo vermelho amarelo, encontrado na região da Baixada Cuiabana, Estado de Mato Grosso, Brasil, local de estudo.

Justifica-se a escolha desse solo pelo fato de que é abundantemente disposto em aterros ou áreas ilegais na região da pesquisa e apresenta adequada composição granulométrica e densidade, possuindo grãos de argila, silte, areia fina e areia média (Figura 1). Essa distribuição favorece a homogeneidade e resistência mecânica do solo-cimento (SERVIÇO..., 2004).

O solo se enquadra na classificação A-4 da Highway Research Board (HBR), com presença de areia fina (39\%), silte (34\%) e argila (24\%). Apresenta características físicas adequadas para estabilização com cimento Portland, com $100 \%$ de material passando na peneira com abertura de malha de 4,75 mm, 53,2\% de teor de finos passantes na peneira com abertura de malha de $0,075 \mathrm{~mm}$, limite de liquidez menor que $45 \%$ e índice de plasticidade inferior a $18 \%$.

\section{Aglomerante e aditivo}

Utilizou-se o cimento CP II Z 32, composto com filler calcário, em virtude de sua secagem rápida e alta resistência mecânica ( $\geq 32 \mathrm{MPa}$ aos 28 dias) e de seu uso corrente nas obras de edificações da construção civil. A caracterização física e mecânica indicou atendimento aos limites estabelecidos nas normativas vigentes. Optou-se por utilizar aditivo superplastificante de pega normal, com composição química à base de éter policarboxilato, com capacidade de proporcionar fluidez às misturas com presença de elevada quantidade de materiais finos, como a do latossolo vermelho amarelo, além de ser um composto amplamente utilizado nas pesquisas de SCAA.

\section{Figura 1 - Distribuição granulométrica do solo latossolo vermelho amarelo}

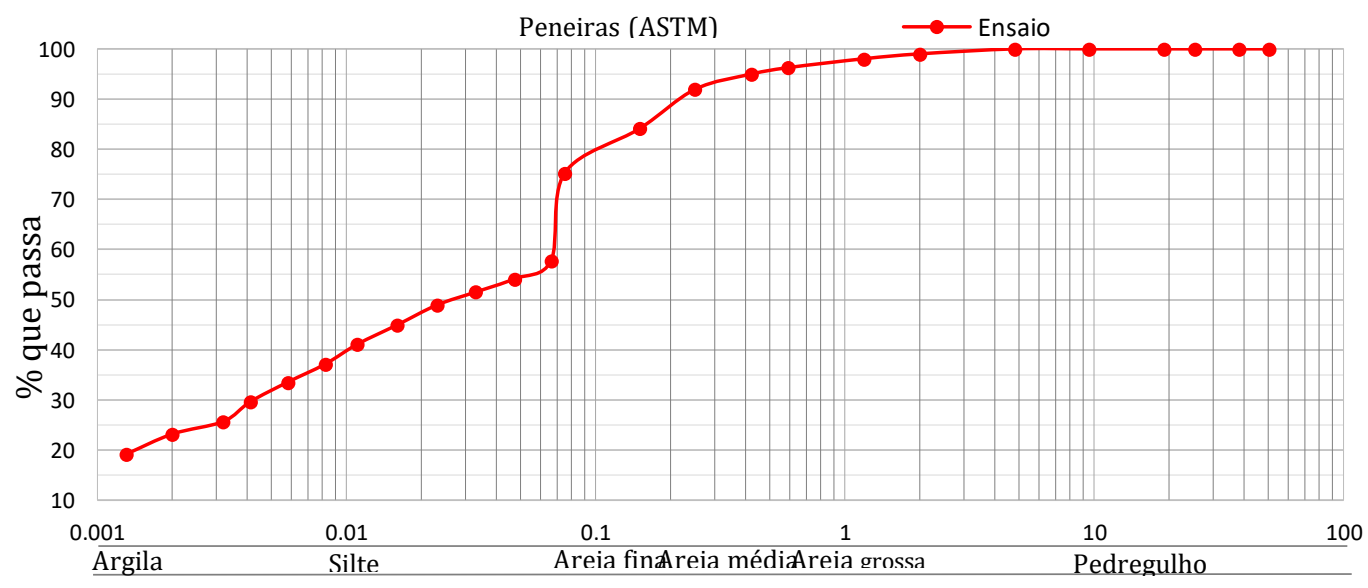

284 Simioni, F. C.; Callekas, I. J. A.; Durante, L. C.; Souza, B. G. de 


\section{Areia de resíduos da construção civil}

Foram caracterizadas as areais de RCC e a areia natural da região da Baixada Cuiabana. A areia reciclada de RCC provém de uma usina de reciclagem local. Sua caracterização indicou densidade de massa aparente de $2,35 \mathrm{~g} / \mathrm{cm}^{3}$, inferior à da areia natural usualmente utilizada na região, que é de $2,65 \mathrm{~g} / \mathrm{cm}^{3}$ e índice de absorção de água de 11\%, atendendo ao limite de 17\% estabelecido pela NBR 15116 (ABNT, 2004).

A composição granulométrica da areia de RCC se enquadra nos limites de distribuição para agregado miúdo previsto para a zona ótima da NBR 7211 (ABNT, 2009), destacando-se que a da areia natural disponível na região permaneceu dentro da zona utilizável (Figura 2).

\section{Método}

\section{Referências normativas e traço da mistura}

Devido à ausência de normativas sobre solo-cimento autoadensável, adotam-se os critérios da norma técnica de paredes monolíticas de solo-cimento convencional (ABNT, 2012d) e, complementarmente, os da norma de concreto autoadensável (ABNT, 2017), nos quesitos de classes de espalhamento, índice de estabilidade visual e classes de viscosidade aparente (t500). Assim, foram definidos os seguintes critérios de desempenho e aceitabilidade para os traços: resistência à compressão maior que 1,0 MPa aos 7 dias de cura, classe de espalhamento SF-2, com diâmetro de espalhamento variando entre $660 \mathrm{~mm}$ e $750 \mathrm{~mm}$ (indicada para a maioria das aplicações correntes) e nível de absorção de água menor ou igual a 20\% (Tabela 1).

Em consulta à bibliografia científica sobre o tema, observou-se grande variabilidade na proporção utilizada entre a massa de cimento e solo (de 1:3,33 a 1:12), com porcentagens de cimento entre $20 \%$ a $30 \%$ em massa de materiais secos (BERTÉ; ALCANTARA, 2013; ALCANTARA; NUNES; RIO, 2014; MILANI; BARBOZA, 2016; FERNANDES, 2017). Como a pesquisa tem enfoque na produção de paredes monolíticas ambientalmente sustentáveis, definiu-se para mistura de solo-cimento autoadensável de referência o menor teor de cimento indicado pela bibliografia, ou seja, $20 \%$ em massa dos materiais secos. Essa premissa pressupõe a menor energia incorporada devido ao cimento. O critério de desempenho mecânico também foi considerado.

A proporção entre cimento e solo de 1:5 foi estabelecida em virtude de esta apresentar, também de acordo com a bibliografia, resistência mecânica compatível com o desempenho requerido (Tabela 1).

Figura 2 - Distribuição granulométrica da areia de RCC e da areia natural da região

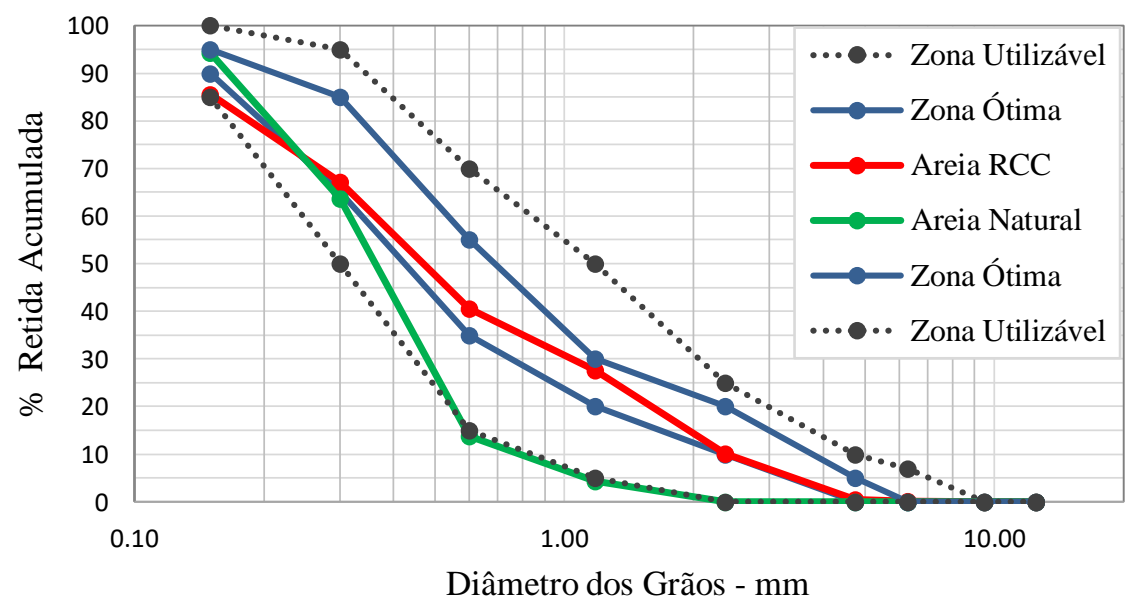

Tabela 1 - Requisitos de desempenho das misturas

\begin{tabular}{c|c|c|c}
\hline $\begin{array}{c}\text { Critério } \\
\text { normativo }\end{array}$ & $\begin{array}{c}\text { Resistencia à } \\
\text { compressão }\end{array}$ & $\begin{array}{c}\text { Espalhamento } \\
\text { requerido }\end{array}$ & $\begin{array}{c}\text { Absorção } \\
\text { de água }\end{array}$ \\
\hline $\begin{array}{c}\text { Desempenho } \\
\text { requerido }\end{array}$ & $\geq 1,0 \mathrm{MPA}$ & $660-750 \mathrm{MM}$ & $\leq 20 \%$ \\
\hline
\end{tabular}


Para estudar a influência da areia de RCC na mistura, a incorporação desse material foi realizada substituindo-se, progressivamente, o solo da mistura de referência em intervalos de 25\%, em massa, mantendo-se constante o fator água/cimento nas misturas (Tabela 2). Dessa forma, com exceção da mistura denominada REF, que apresenta $100 \%$ de massa de solo e da mistura $100 \%$ RCC, que apresenta $100 \%$ de areia de RCC, as demais composições apresentam misturas híbridas de solo e areia de RCC com proporções intermediárias.

Para manter o fator água/cimento constante foi necessário variar a porcentagem de aditivo nas misturas para garantir a fluidez adequada ao critério de espalhamento estabelecido na Tabela 1. Assim, realizou-se estudo de pré-dosagem, o qual indicou a dispensa de aditivo para alcançar a fluidez almejada em 100\% RCC, bem como as proporções requeridas para cada um dos demais traços, destacando-se que à medida que se incorporou a areia de RCC na mistura, reduziu-se progressivamente o teor de aditivo requerido pela mistura (Tabela 2).

\section{Moldagem e caracterização física e mecânica das misturas}

As misturas foram feitas em um recipiente levemente umedecido, com a finalidade de manter o fator a/c constante durante as dosagens. Em seu interior foram acondicionados os materiais secos: solo, cimento e areia de RCC, manualmente homogeneizados (Figura 3a). A água foi adicionada à mistura em três etapas: inicialmente, o primeiro terço foi despejado, procedendo-se à homogeneização da mistura por dois minutos; na sequência, ao segundo terço, foi adicionado o aditivo superplastificante, procedendo-se novamente à homogeneização da mistura por três minutos; por fim, foi adicionado o terço final, finalizando o procedimento (Figura 3b). Previamente à realização dos ensaios no estado fresco, sempre tomou-se a precaução de homogeneizar a mistura antes da sua colocação nos equipamentos de ensaios e moldes dos corpos de prova.

Para a caracterização das misturas REF a 100\% RCC foram realizados ensaios nos estados fresco e endurecido, seguindo as normas indicadas na Figura 4.

A caracterização do comportamento das misturas no estado fresco foi realizada por meio dos ensaios de espalhamento (ABNT, 2017), funil (ABNT, 2013), densidade de massa e teor de ar incorporado (ABNT, 2005b). Ressalta-se que no ensaio do funil, o funil de Marsh com diâmetro de abertura $8 \mathrm{~mm}$ recomendado pela norma foi substituído pelo modelo derivado de garrafas PET, que permite que a massa escoe livremente devido a sua abertura maior, conforme recomendado por Berté (2012).

Tabela 2 - Misturas de SCAA com incorporação de RCC

\begin{tabular}{c|c|c|c|c|c|c}
\hline Mistura & Solo & Cimento & Água & Aditivo & Rcc & Fator A/C \\
\hline Ref & $\mathbf{1 0 0 \%}$ & $\mathbf{2 0 \%}$ & $\mathbf{2 7 \%}$ & $\mathbf{1 , 6 \%}$ & $\mathbf{0 \%}$ & $\mathbf{1 , 6 2}$ \\
\hline $25 \%$ RCC & $75 \%$ & $20 \%$ & $27 \%$ & $1,2 \%$ & $25 \%$ & 1,62 \\
$50 \%$ RCC & $50 \%$ & $20 \%$ & $27 \%$ & $0,8 \%$ & $50 \%$ & 1,62 \\
$75 \%$ RCC & $25 \%$ & $20 \%$ & $27 \%$ & $0,4 \%$ & $75 \%$ & 1,62 \\
$100 \%$ RCC & $0 \%$ & $20 \%$ & $27 \%$ & $0 \%$ & $100 \%$ & 1,62 \\
\hline
\end{tabular}

Figura 3 - Procedimento de mistura: (a) estado seco e (b) estado fresco

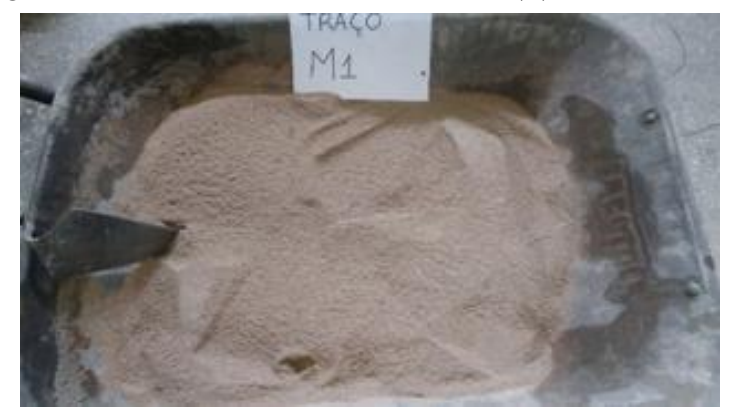

(a)

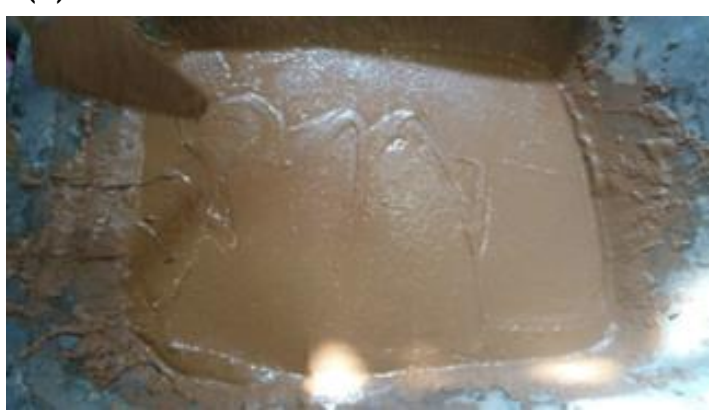

(b)

286 Simioni, F. C.; Callekas, I. J. A.; Durante, L. C.; Souza, B. G. de 
Figura 4 - Diagrama com a indicação normativa dos ensaios de caracterização das misturas

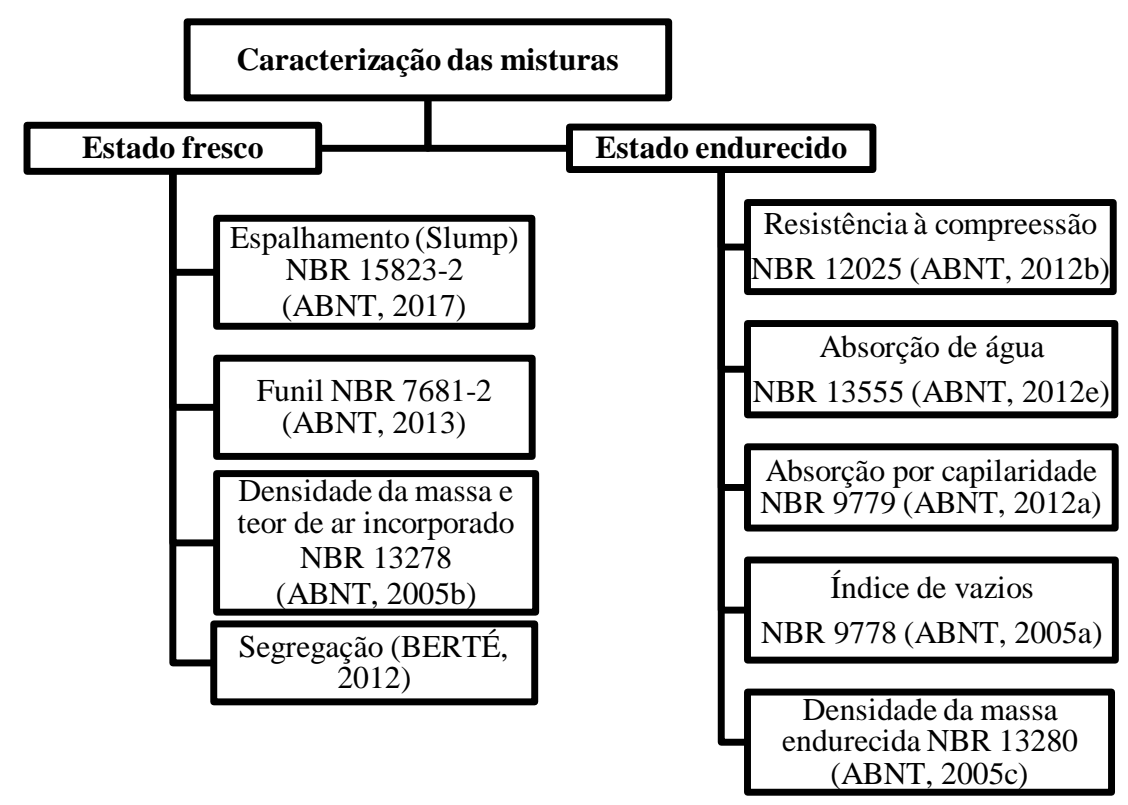

A caracterização do comportamento das misturas no estado endurecido foi realizada por meio dos ensaios de resistência à compressão simples aos 7, 14 e 28 dias (ABNT, 2012b), ensaio de absorção de água (ABNT, 2012e), ensaio de índice de vazios (ABNT, 2005a) e densidade da massa aparente (ABNT, 2005c). Os corpos de prova foram moldados sem adensamento com haste, desmoldados após 48h de cura e armazenados em câmara úmida para posterior realização dos ensaios de resistência à compressão nas resistências indicadas. O teor de absorção de água por capilaridade $\left(\mathrm{g} / \mathrm{cm}^{2}\right)$ e o índice de vazios foram avaliados aos sete dias de idade e o teor de absorção de água em porcentagem aos sete e 28 dias.

Esses ensaios requerem a confecção de corpos de prova, sendo utilizados três para cada ensaio de resistência à compressão simples aos 7, 14 e 28 dias, três para absorção de água por capilaridade e três para determinação de índice de vazios (estes também foram utilizados para determinação de densidade de massa endurecida), totalizando a confecção de 90 corpos de prova com dimensões de $50 \mathrm{~mm}$ x $100 \mathrm{~mm}$ para as cinco misturas pesquisadas.

\section{Resultados e discussões}

\section{Caracterização das misturas no estado fresco}

Ao se manter o fator água/cimento constante à medida que o teor de resíduos era aumentado, observou-se a influência da adição do agregado reciclado na trabalhabilidade da mistura, assim como a do aditivo. Constatou-se a elevação dos diâmetros de espalhamento à medida que a quantidade de solo foi reduzida na mistura e a areia de RCC era incorporada (Tabela 3). Nesse ponto é importante destacar que o aditivo se faz necessário para manter a homogeneidade e melhorar a fluidez da massa, mantendo-a próximo aos limites estabelecidos da NBR 15823-2 (ABNT, 2017) para a maioria das aplicações de uso corrente. Nota-se que as misturas REF e $100 \%$ RCC tiveram os valores de espalhamento fora dos limites estabelecidos pela norma. Justifica-se esse comportamento pelo fato de a quantidade de aditivo adotada em cada mistura ser a estritamente necessária para fazer com que as misturas híbridas, foco desta pesquisa, ficassem o mais próximo possível dos limites normativos, o que foi feito por meio de estudo pré-dosagem, conforme anteriormente citado.

Focando-se nas misturas híbridas, que ainda se caracterizam como solo-cimento (porcentagem de solo $\geq$ $50 \%$ ), notou-se na de $25 \%$ RCC e na de $50 \%$ RCC os menores desvios padrões nos diâmetros de espalhamento medidos, garantindo-se dessa forma maior homogeneidade, resultado do adequado entrosamento das partículas do solo e da areia reciclada. Esse fato influencia na resistência mecânica desses compósitos, conforme será apresentado posteriormente. Entre as misturas, a $100 \%$ RCC foi a única a apresentar leve franja de água na circunferência do círculo formado e empilhamento de agregados no centro 
da argamassa, ambos conferidos qualitativamente por meio do índice de estabilidade visual. Esse comportamento pode ter sido causado pela falta de partículas de ligação, função desempenhada pela diferença granulométrica dos componentes da mistura, ocasionando pouca homogeneidade da argamassa e o fenômeno de exsudação. Esses resultados são compatíveis com os encontrados por Barboza (2014), quanto à consistência do solo-cimento autoadensável. De acordo com o autor, as misturas de SCAA 1/8 (cimento/solo) e SCAA 1/12 (cimento/solo) sem adição de aditivos superplastificantes também apresentaram índice de estabilidade visual instável (IEV2) com exsudação, tal como o verificado no presente estudo.

O ensaio do funil visa determinar a taxa de escoamento e o índice de fluidez das misturas, ou seja, a vazão mássica das misturas. Por meio desses ensaios, foi possível constatar que a mistura REF e a $100 \%$ RCC apresentam velocidade de fluidez menor que as misturas híbridas (Tabela 3, Figura 3). A primeira era composta por $100 \%$ de solo com elevada presença de material fino na mistura, o que pode ter dificultado o escoamento, apesar da utilização do aditivo. A segunda apresentava $100 \%$ de areia, com grãos maiores, mas não dispunha de aditivo que melhorasse a coesão entre as partículas, o que corrobora com a diminuição da velocidade de escoamento. Além disso, como relatado, na mistura 100\% RCC foi observado o fenômeno de exsudação e a separação da água da massa, o que também dificulta o seu escoamento. As maiores taxas de escoamento verificadas nas misturas com porcentagens intermediárias de areia de RCC decorrem da substituição de finos por partículas maiores. O uso do aditivo melhora a coesão entre as partículas, enquanto o formato dessas últimas favorece a mobilidade devido a sua ação esférica, facilitando o escoamento.

Em termos gerais, nota-se elevação da vazão mássica no funil com o aumento do diâmetro de espalhamento das misturas (Figura 5). As misturas de 50\% RCC e 75\% RCC apresentaram as maiores vazões mássicas, ocasionando um pequeno avanço no espalhamento em relação ao limite definido para o desempenho das misturas. Esse fato pode ser contornado com a redução de aditivo plastificante. Llajaruna (2017), em estudo com incorporação de areia de resíduo de construção em até $40 \%$, observou redução no diâmetro de espalhamento à medida que se incorporava o resíduo (de $427 \mathrm{~mm}$ para $408 \mathrm{~mm}$ ), justificado pela manutenção constante do teor de aditivo nas misturas, diferentemente do que ocorreu nesta pesquisa, na qual, no estudo de pré-dosagem, observou-se a necessidade de elevar a quantidade de aditivo plastificante a ser adicionada.

Tabela 3 - Valores médios dos ensaios de caracterização no estado fresco

\begin{tabular}{|c|c|c|c|c|c|c|c|c|c|}
\hline \multirow{2}{*}{ Mistura } & \multicolumn{2}{|c|}{$\begin{array}{c}\text { Ensaio de } \\
\text { espalhamento }\end{array}$} & \multirow{2}{*}{ IEV } & \multicolumn{2}{|c|}{ Funil } & \multicolumn{2}{|c|}{$\begin{array}{c}\text { Segregação } \\
(\%)\end{array}$} & \multirow{2}{*}{$\begin{array}{c}\text { Densidade } \\
\text { de massa } \\
\left(\mathrm{g} / \mathrm{cm}^{3}\right)\end{array}$} & \multirow{2}{*}{$\begin{array}{l}\text { Teor de ar } \\
\text { incorporado } \\
(\%)\end{array}$} \\
\hline & $\begin{array}{c}\text { Diâmetro } \\
(\mathbf{c m})\end{array}$ & T500 (s) & & (s) & $(\mathrm{g} / \mathrm{s})$ & $\begin{array}{l}\# 4,8 \\
\mathrm{~mm}\end{array}$ & $\begin{array}{l}\# 2,4 \\
\mathrm{~mm}\end{array}$ & & \\
\hline REF & 555 & $0,97 \pm 2,12 *$ & IEV0 & 10,9 & 165,2 & 70,8 & 97,7 & 1,88 & 19,5 \\
\hline $25 \% \mathrm{RCC}$ & 662 & $0,81 \pm 0,71$ & IEV0 & 2,5 & 737,7 & 63,1 & 100 & 1,92 & 17,6 \\
\hline $50 \%$ RCC & 770 & $0,58 \pm 1,41$ & IEV0 & 2,3 & 782,6 & 65,4 & 94,9 & 1,96 & 15,5 \\
\hline $75 \% \mathrm{RCC}$ & 772 & $0,56 \pm 1,77$ & IEV1 & 2,2 & 810,8 & 68,4 & 95,8 & 1,93 & 16,8 \\
\hline $100 \% \mathrm{RCC}$ & 570 & $0,51 \pm 2,83$ & IEV2 & 8,9 & 202,3 & 91,2 & 95,4 & 1,89 & 17,7 \\
\hline
\end{tabular}

Nota: *desvio padrão; e IEV - Índice de estabilidade visual.

Figura 5 - Relação entre diâmetro de espalhamento e vazão mássica

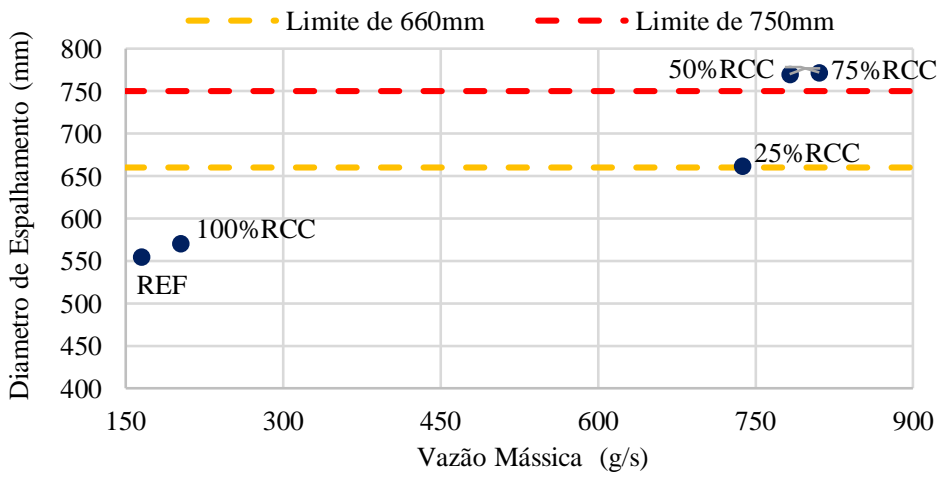

288 Simioni, F. C.; Callekas, I. J. A.; Durante, L. C.; Souza, B. G. de 
Contatou-se que as misturas com menor diâmetro de espalhamento apresentaram maior tempo de escoamento e aquelas com maior diâmetro apresentaram maior fluidez (Figura 6). Isso implica dizer que tempo de escoamento e diâmetro de espalhamento são grandezas inversamente proporcionais. Esse comportamento se assemelha ao observado por Alcantara, Nunes e Rio (2014), em estudo de misturas de SCAA, no qual as que apresentaram diâmetros de espalhamento entre $200 \mathrm{~mm}$ e $260 \mathrm{~mm}$ tiveram tempo de escoamento superiores a 2,07 segundos, e nas com diâmetros maiores que $300 \mathrm{~mm}$, o tempo de escoamento foi menor que 1,6 segundo.

A mistura $100 \%$ RCC apresentou a maior porcentagem de concentração de material retido na peneira 4,8 $\mathrm{mm}$, decorrente da sua baixa fluidez, conforme constatado no ensaio de espalhamento e fluidez (Tabela 3). Além disso, os baixos valores de retenção observados na mistura $100 \%$ RCC podem ser ocasionados pela ausência de finos, decorrente da substituição total do solo. Nas misturas $25 \%$ RCC, 50\% RCC e $75 \%$ RCC, observou-se maior uniformidade na porcentagem de retenção entre as peneiras, fato que pode ser explicado pelo maior entrosamento entre os constituintes, conforme destacado por Reis (2017).

Ao se relacionar a porcentagem retida nas peneiras ensaiadas (Figura 7), notou-se certa proporcionalidade entre os resultados, com concentração retida semelhante de uma peneira em relação à outra, com exceção da mistura 100\% RCC, que em virtude da ausência de aditivo, praticamente todo o material ficou retido tanto na peneira \#4,76 mm e \#2,38 mm. A exsudação observada nessa mistura pode ter contribuído para esse comportamento. Nota-se que quanto maior é a quantidade de material retido na peneira \#4,76 mm, maior também é na peneira de \#2,38 mm, fato esse já observado por Berté (2012).

Constatou-se reduzida variação da densidade da massa nas cinco misturas em virtude das massas específicas aparentes do solo e da areia de RCD serem semelhantes (Tabela 3). Até na mistura 50\% RCD ocorreu redução do teor de ar incorporado, a partir do qual se nota, então, elevação dessa propriedade, de onde se pode inferir que, caso se queira atender especificamente esse critério de desempenho, a melhor mistura testada é a 50\% RCC. Não foi possível estabelecer relação entre a densidade da massa no estado fresco e o teor de ar incorporado nas misturas (Figura 8). O comportamento corrobora com Barboza (2014), que determinou reduzida variação de densidades no estado fresco $\left(2,69 \mathrm{~g} / \mathrm{cm}^{3}\right.$ e $\left.2,61 \mathrm{~g} / \mathrm{cm}^{3}\right)$ e de teores de ar incorporados nas misturas de SCAA (26\% e $30 \%)$.

Figura 6 - Relação entre diâmetro de espalhamento e tempo de escoamento

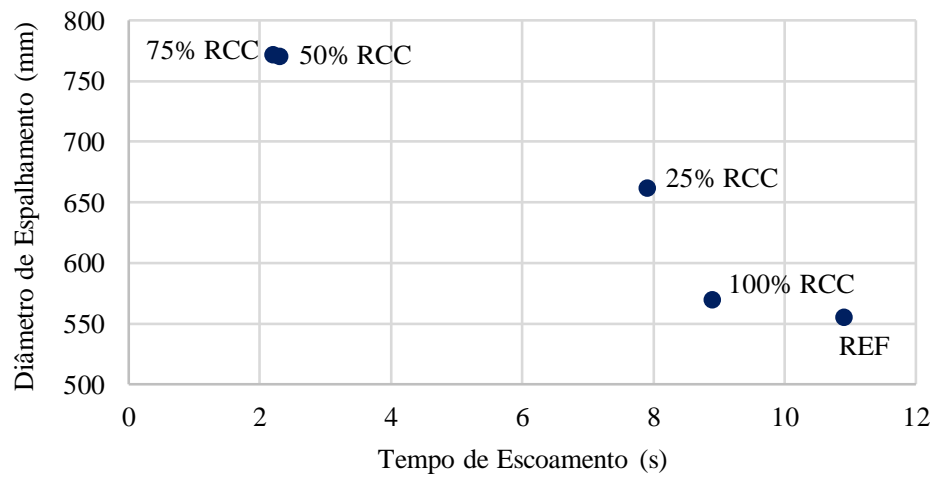

Figura 7 - Retenção determinada para as misturas entre as peneiras \#2,4 mm e \#4,8 mm

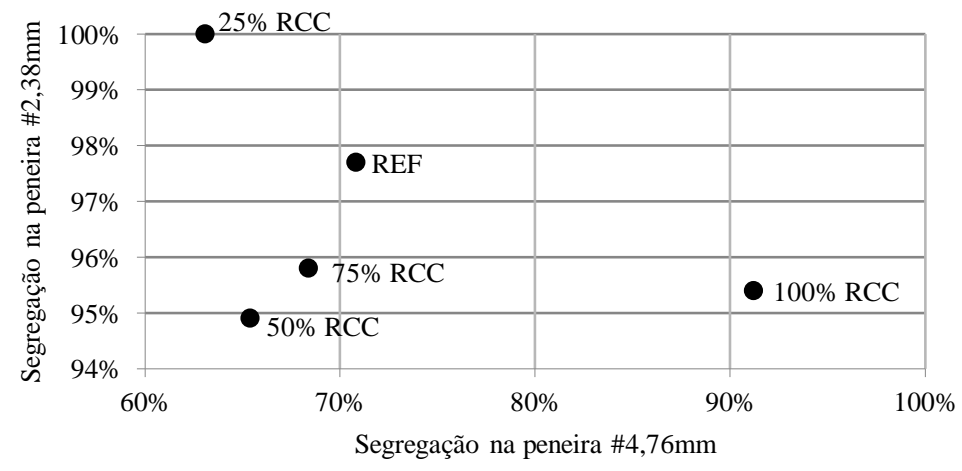


Figura 8 - Densidade da massa em relação ao teor de ar incorporado

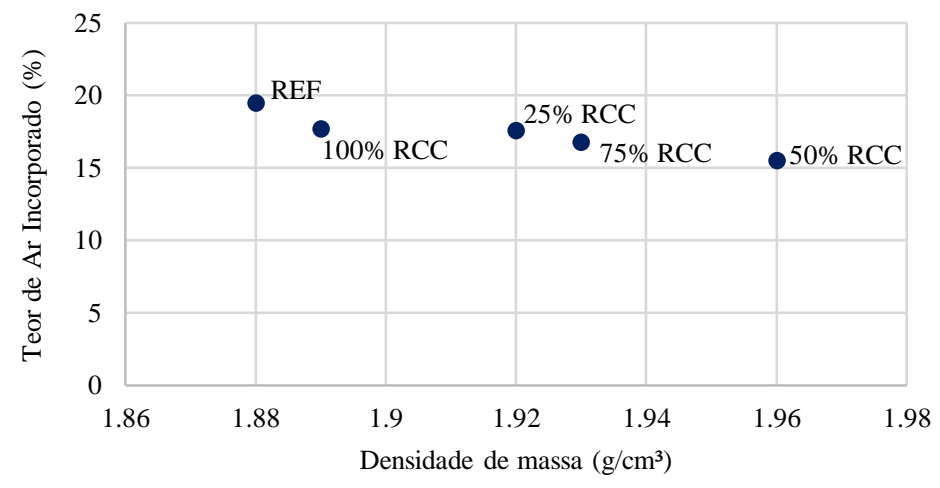

\section{Caracterização das misturas no estado endurecido}

Constata-se que apenas a mistura REF não se enquadrou no limite de 20\%, estabelecido pela NBR 13555 (ABNT, 2012e) (Tabela 4). Observou-se redução percentual dos valores de absorção de água com o tempo de cura dos corpos de prova (aos 28 dias, os valores percentuais foram inferiores aos de 7 dias). Esse comportamento também foi identificado por Llajaruna (2017), em misturas de solo-cimento com adição de resíduos, nas quais os valores de absorção de água estão diretamente relacionados com a quantidade de resíduos presentes nas misturas, ocorrendo diminuição desse índice em função do tempo de cura. No estudo desse autor, a mistura de referência obteve $31 \%$ de absorção, enquanto nas com $10 \%$ e $20 \%$ de incorporação de RCC a absorção se manteve em $24 \%$ aos 28 dias, e aos 56 dias de cura os valores diminuíram para $19 \%$. Relaciona-se esse comportamento ao desenvolvimento dos enlaces desencadeados pelo processo de hidratação do cimento na mistura, que ocorrem especialmente com os silicatos, logo após o início de pega do cimento e continua ao longo do tempo, preenchendo os espaços ocupados previamente pela água e pelas partículas de cimento em dissolução (VIECILI; HASTENPFLUG; GIRARDI, 2018).

Ao se analisar as misturas híbridas, notou-se que a 25\% RCC foi a que apresentou menor índice de absorção de água tanto em termos percentuais quanto em $\mathrm{g} / \mathrm{cm}^{2}$, ocorrendo elevação dos valores a partir da mistura $50 \%$ RCC (Tabela 4). A mistura 100\% RCC, ou seja, apenas com areia, foi a que apresentou menor absorção percentual, igualando-se em termos absolutos a $25 \% \mathrm{RCC}$, em virtude da ausência de materiais finos, o que dificulta a subida da água pelos capilares. Dessa forma, a mistura híbrida 25\% RCC apresentou melhor desempenho, indicando que, segundo essa propriedade, é a mais adequada para uso em paredes monolíticas, apesar do atendimento das demais, com exceção da mistura de referência (REF). Os resultados encontrados por Barboza (2014), no ensaio de capilaridade de misturas de SCAA com relação cimento/solo de 1:8 a 1:12 com adição de $0,8 \%$ e $1,2 \%$ de aditivo foram de $1,42 \mathrm{~g} / \mathrm{cm}^{2}$ para a primeira mistura e $1,46 \mathrm{~g} / \mathrm{cm}^{2}$ para a segunda, inferiores aos encontrados nesta pesquisa.

O ensaio de índice de vazios busca traduzir a estrutura interna dos corpos de prova no estado endurecido, não sendo capaz de mensurar os vazios internos que não estão ligados com o meio externo. O menor valor foi observado na mistura 100\% RCC. Para as misturas híbridas, a 75\% RCC apresentou o menor valor. Notou-se a existência de diminuição do índice de vazios à medida que se incorpora os resíduos de areia nas misturas de SCAA (Figura 9). Não há um limite normativo estabelecido para essa propriedade física, no entanto esses resíduos se apresentam acima do determinado por Barboza (2014), segundo o qual misturas com relação 1:8 e 1:12 (cimento/agregados) com 0,8\% e 1,2\% de aditivo, respectivamente, apresentaram índice de vazios na ordem de $20 \%$.

Infere-se a existência de uma relação entre os vazios existentes no estado endurecido e a quantidade de aditivo adicionado na fase de produção das misturas (Figura 10). Dessa forma, recomenda-se sempre que possível dosar as misturas com o mínimo de aditivo, utilizando apenas a quantidade necessária para garantir adequada trabalhabilidade e espalhamento, os quais devem ser previamente estabelecidos a partir de critérios de desempenho.

Acerca dos resultados de densidade de massa aparente e resistência mecânica média em função do tempo de cura dos corpos de prova, as cinco misturas alcançaram limites superiores aos estabelecidos pela NBR 13553 (2012d), ou seja, superior a 1,0 MPa aos 7 dias (Tabela 5). Em todas as misturas observou-se elevação da resistência com a idade. No entanto, ocorreu menor taxa de elevação da resistência mecânica nas misturas com maior porcentagem de incorporação de resíduos (75\% RCC e 100\% RCC). Os valores encontrados nas

290 Simioni, F. C.; Callekas, I. J. A.; Durante, L. C.; Souza, B. G. de 
misturas foram superiores a 3,0 MPa, aproximando-se dos encontrados por Berté e Alcântara (2013), em misturas de solo-cimento, em que as resistências mecânicas variaram entre 2,70 MPa e 4,43 MPa, aos 28 dias de idade. Constata-se que a incorporação de RCC é benéfica às misturas hibridas até certo limite, compreendido entre $25 \%$ e $50 \%$, a partir do qual se nota decréscimo da resistência à compressão. Na pesquisa de Llajaruna (2017), os valores variaram de 4,36 MPa a 3,68 MPa, para as incorporações entre $10 \mathrm{e}$ $40 \%$, com melhor resistência à compressão sendo alcançada com teores de incorporação de $20 \%$ de RCC.

Tabela 4 - Valores médios ( \pm desvio padrão) dos ensaios de absorção de água, absorção por capilaridade e índice de vazios aos 28 dias de idade

\begin{tabular}{c|c|c|c}
\hline Mistura & $\begin{array}{c}\text { Absorção de } \\
\text { água (\%) }\end{array}$ & $\begin{array}{c}\text { Absorção de água por } \\
\text { capilaridade }\left(\mathbf{g} / \mathbf{c m}^{2}\right)\end{array}$ & $\begin{array}{c}\text { Índice de vazios } \\
(\mathbf{\%})\end{array}$ \\
\hline Ref & $\mathbf{2 1 , 3 \pm 1 , 9 9 *}$ & $\mathbf{3 , 9 9} \pm \mathbf{0 , 2 3}$ & $\mathbf{2 6 , 5} \pm \mathbf{2 , 0 1}$ \\
\hline $25 \%$ RCC & $19,4 \pm 1,06$ & $3,42 \pm 0,17$ & $24,6 \pm 1,14$ \\
$50 \%$ RCC & $19,5 \pm 6,53$ & $4,25 \pm 0,10$ & $27,1 \pm 1,20$ \\
$75 \%$ RCC & $19,5 \pm 5,95$ & $3,88 \pm 0,12$ & $24,0 \pm 0,46$ \\
$100 \%$ RCC & $17,6 \pm 8,71$ & $3,42 \pm 0,12$ & $22,9 \pm 1,44$ \\
\hline
\end{tabular}

Nota: *desvio padrão.

Figura 9 - Relação entre o índice de vazios nas misturas e quantidade de areia reciclada incorporada

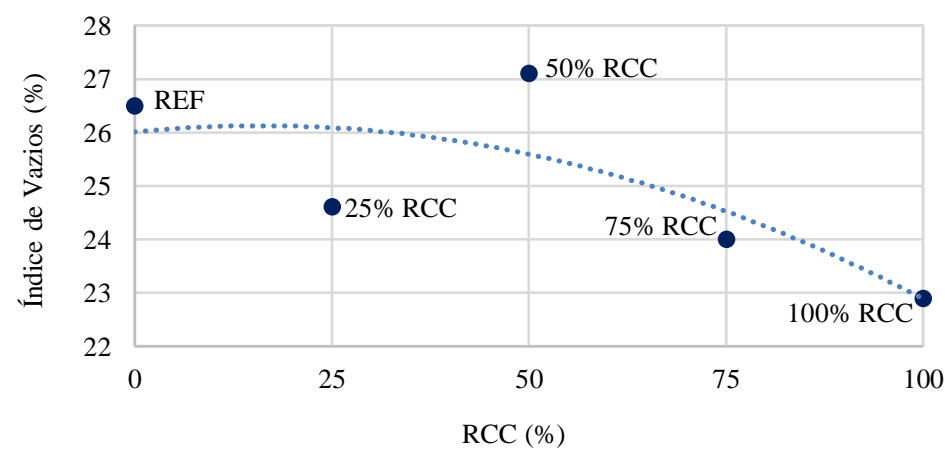

Figura 10 - Relação entre o índice de vazios e a quantidade de aditivo utilizado nas misturas

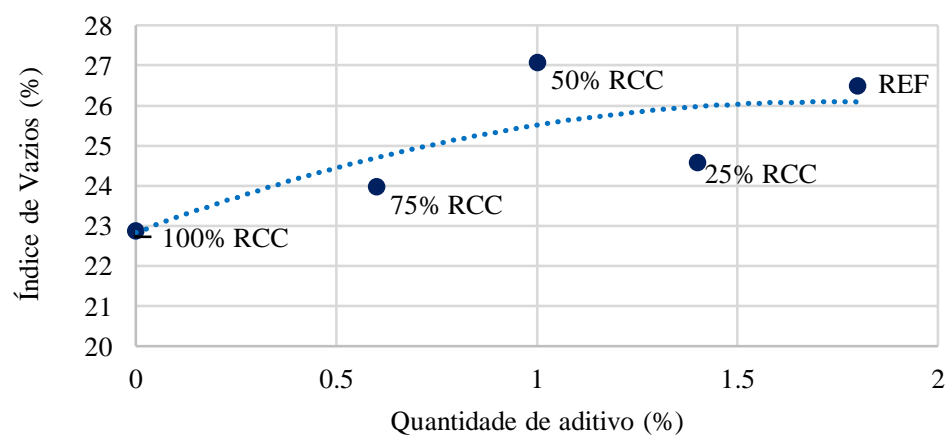


Acerca dos resultados de densidade de massa aparente e resistência mecânica média em função do tempo de cura dos corpos de prova, as cinco misturas alcançaram limites superiores aos estabelecidos pela NBR 13553 (2012d), ou seja, superior a 1,0 MPa aos 7 dias (Tabela 5). Em todas as misturas observou-se elevação da resistência com a idade. No entanto, ocorreu menor taxa de elevação da resistência mecânica nas misturas com maior porcentagem de incorporação de resíduos (75\% RCC e 100\% RCC). Os valores encontrados nas misturas foram superiores a 3,0 MPa, aproximando-se dos encontrados por Berté e Alcântara (2013), em misturas de solo-cimento, em que as resistências mecânicas variaram entre 2,70 MPa e 4,43 MPa, aos 28 dias de idade. Constata-se que a incorporação de RCC é benéfica às misturas hibridas até certo limite, compreendido entre $25 \%$ e $50 \%$, a partir do qual se nota decréscimo da resistência à compressão. Na pesquisa de Llajaruna (2017), os valores variaram de 4,36 MPa a 3,68 MPa, para as incorporações entre 10 e $40 \%$, com melhor resistência à compressão sendo alcançada com teores de incorporação de $20 \%$ de RCC.

A maior resistência mecânica foi observada na mistura $25 \%$ RCC, provavelmente devido ao melhor entrosamento entre as partículas, tendo em vista que a elevação da densidade aparente também foi observada (Figura 11).

A partir da incorporação de $50 \%$ de areia de RCC, ocorreu decaimento da resistência à compressão e da densidade aparente. Isso indica a possibilidade de existência de um valor ótimo de incorporação de resíduos compreendido entre misturas com valores inferiores a 50\% de RCC. A confirmação desse fato requer a realização de ensaios com valores de resíduos entre nos intervalos entre $25 \%$ e $50 \%$. O comportamento se assemelha ao encontrado por Reis (2017), que durante a execução de tijolos de solo-cimento com resíduos de RCC observou que o comportamento da mistura solo $25 \%$ de RCC alcançou as maiores resistências mecânicas (2,18 MPa). Em outro estudo, Cardoso (2017) encontrou valores de resistência à compressão para argamassa com incorporação de resíduos de RCC de 5,4 MPa, 5,9 MPa, 5,9 MPa e 5,70 MPa para teores de incorporação de $10 \%, 20 \%, 30 \%$ e $40 \%$, respectivamente. Nota-se que a partir de $40 \%$ de adição de resíduos na mistura, a resistência diminui, ratificando o comportamento observado nesta pesquisa.

Não foi possível estabelecer uma relação entre a densidade específica aparente e resistência à compressão simples dos corpos de prova no estado endurecido, justificado pelo fato de haver baixa variação entre as massas específicas aparentes da areia de $\operatorname{RCC}\left(2,31 \mathrm{~g} / \mathrm{cm}^{3}\right)$ do solo $\left(2,27 \mathrm{~g} / \mathrm{cm}^{3}\right)$.

Tabela 5 - Valores médios dos ensaios de densidade e resistência à compressão simples

\begin{tabular}{c|c|c|c|c}
\hline Mistura & $\begin{array}{c}\text { Densidade de massa } \\
\text { aparente }\left(\mathbf{g} / \mathbf{c m}^{\mathbf{3}}\right)\end{array}$ & $\begin{array}{c}\text { Resistência 7 } \\
\text { dias (MPa) }\end{array}$ & $\begin{array}{c}\text { Resistência 14 } \\
\text { dias (MPa) }\end{array}$ & $\begin{array}{c}\text { Resistência 28 } \\
\text { dias (MPa) }\end{array}$ \\
\hline Ref & $\mathbf{1 , 7 8} \pm \mathbf{0 , 1 4}$ & $\mathbf{1 , 7 1} \pm \mathbf{0 , 0 4}$ & $\mathbf{2 , 4 9} \pm \mathbf{0 , 2 8}$ & $\mathbf{3 , 5 6} \pm \mathbf{0 , 1 8}$ \\
\hline $25 \%$ RCC & $1,92 \pm 0,24$ & $2,17 \pm 0,07$ & $2,95 \pm 0,18$ & $3,97 \pm 0,17$ \\
$50 \%$ RCC & $1,90 \pm 0,01$ & $1,81 \pm 0,11$ & $2,48 \pm 0,13$ & $3,74 \pm 0,12$ \\
$75 \%$ RCC & $1,88 \pm 0,03$ & $2,05 \pm 0,05$ & $2,62 \pm 0,03$ & $3,26 \pm 0,12$ \\
$100 \%$ RCC & $1,97 \pm 0,01$ & $2,27 \pm 0,24$ & $2,83 \pm 0,03$ & $3,32 \pm 0,07$ \\
\hline
\end{tabular}

Figura 11 - Resistência média à compressão em função do teor de incorporação de resíduos aos 28 dias de idade

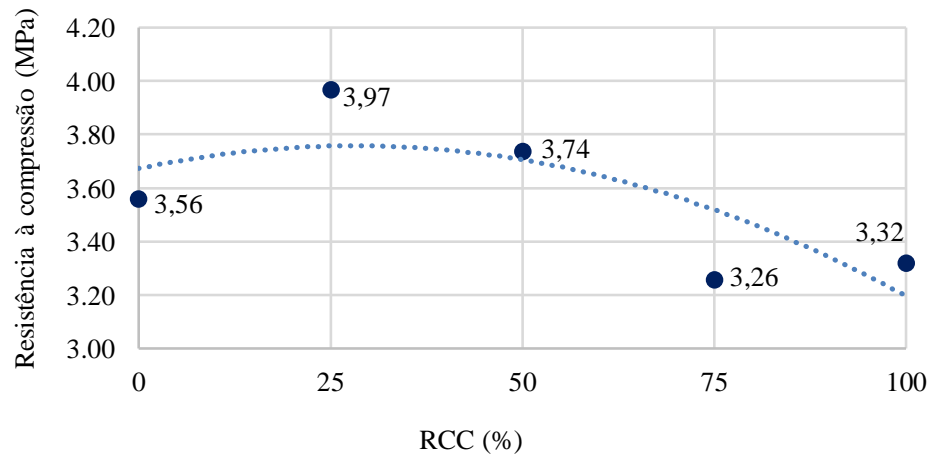

292 Simioni, F. C.; Callekas, I. J. A.; Durante, L. C.; Souza, B. G. de 


\section{Considerações finais}

A incorporação de areia de RCC em sistemas de vedação vertical monolíticos em solo-cimento autoadensável conduz a um material ambientalmente mais sustentável, com menor energia incorporada, uma vez que se buscou selecionar um traço com menor quantidade percentual de cimento em relação à massa de solo. Para tanto foram estudados um traço de referência, sem incorporação de areia de RCC, denominada REF, e outros quatro traços, com incorporação de $25 \%, 50 \%, 75 \%$ e $100 \%$ de areia de RCC, denominados $25 \%$ RCC, $50 \%$ RCC, $75 \%$ RCC e $100 \%$ RCC, respectivamente.

Considerando-se as propriedades no estado fresco, as misturas híbridas apresentaram adequada fluidez, com a mistura $25 \%$ RCC, atendendo os limites normativos especificados. As misturas $50 \%$ RCC e $75 \%$ RCC necessitam de uma pequena redução de aditivo plastificante para que atendam a esse critério.

Observou-se na mistura 100\% RCC que não houve adequada homogeneização, resultando em segregação dos constituintes e exsudação da água de mistura. Já a mistura REF não apresentou fluidez suficiente para atendimento do requisito de desempenho especificado, em virtude da baixa vazão mássica e diâmetros de espalhamento com aberturas inferiores às estabelecidas como referência. As misturas $25 \%$ RCC e $50 \%$ RCC apresentaram os melhores índices de estabilidade visual e menores desvios padrões, indicando maior entrosamento das partículas nesse intervalo de incorporação.

O uso de aditivo superplastificante é essencial para melhorar a fluidez das misturas, e quanto maior a quantidade adicionada à mistura maior é o índice de vazios na fase de estado endurecido. Assim, este deve ser sempre aplicado em quantidade mínima na confecção das misturas, visando reduzir a absorção de água por capilaridade e, também, elevar a resistência mecânica, uma vez que essas propriedades se relacionam com a estrutura interna dos vazios. Também se constatou que a areia de RCC contribui para a redução do uso de aditivo, pois sua incorporação melhora a homogeneidade e aumenta a fluidez das misturas, podendo dessa forma também contribuir para a redução do uso de aditivo.

$\mathrm{Na}$ fase de estado endurecido a incorporação de areia de RCC também melhorou os índices de absorção de água em todas as misturas híbridas, enquadrando-as nos limites estabelecidos pela norma. Destaque para mistura de referência (REF) que não atendeu a esse requisito, em virtude da maior quantidade de finos presentes na amostra, o que favorece a absorção de água por capilaridade. As resistências mecânicas também foram influenciadas pela incorporação de areia de RCC, notando-se elevação até $50 \%$ de incorporação, a partir do qual ocorre a diminuição da resistência, fato que expressa a saturação do agregado reciclado na mistura. A mistura 25\% RCC obteve a maior resistência se comparada às demais, recomendando-se, portanto, que se conduza um estudo secundário visando encontrar o teor ideal de incorporação sob o ponto de vista mecânico.

Evidencia-se, portanto, que a incorporação de resíduos da construção civil, na forma de areia, em misturas de solo-cimento autoadensável apresenta potencial para confecção de sistemas verticais de vedação monolíticos, uma vez que se verificou enquadramento nos requisitos de desempenho estabelecidos pelas normas técnicas. Como todas as misturas híbridas atenderam ao requisito normativo de resistência mecânica e absorção de água por capilaridade, recomenda-se como continuidade desta pesquisa a realização de ensaios de retração e fissuração para identificar o teor ideal de incorporação levando-se em consideração também essas propriedades, uma vez que essas argamassas são muitos suscetíveis a esses efeitos.

\section{Referências}

AGOPYAN, V.; JOHN, V. M. O desafio da sustentabilidade na construção civil. São Paulo: Edgard Blücher, 2011.

ALCANTARA, M. A. M; NUNES, S. C. B; RIO, J. F. M. E. Estudo do solo-cimento-auto adensável produzido com solos da região do Porto-PT: parte II: avaliação da resistência e desempenho mecânico por meio da medição da resistividade elétrica e velocidade de propagação de ondas de ultrassom. REEC Revista Eletrônica de Engenharia Civil, v. 9, n. 1, p. 52-64, 2014.

ASSOCIAÇÃO BRASILEIRA DE NORMAS TÉCNICAS. NBR 12025: solo-cimento: ensaio de compressão simples de corpos de prova cilíndricos: método de ensaio. Rio de Janeiro, $2012 \mathrm{~b}$.

ASSOCIAÇÃO BRASILEIRA DE NORMAS TÉCNICAS. NBR 12253: solo-cimento: dosagem para emprego como camada de pavimento: procedimento. Rio de Janeiro: 2012c. 
ASSOCIAÇÃO BRASILEIRA DE NORMAS TÉCNICAS. NBR 13278: argamassa para assentamento e revestimento de paredes e tetos: determinação da densidade de massa e do teor de ar incorporado. Rio de Janeiro, 2005b.

ASSOCIAÇÃO BRASILEIRA DE NORMAS TÉCNICAS. NBR 13280: argamassa para assentamento e revestimento de paredes e tetos: determinação da densidade de massa aparente no estado endurecido. Rio de Janeiro, 2005c.

ASSOCIAÇÃO BRASILEIRA DE NORMAS TÉCNICAS. NBR 13553: materiais para emprego em parede monolítica de solo-cimento sem função estrutural: requisitos. Rio de Janeiro, 2012d.

ASSOCIAÇÃO BRASILEIRA DE NORMAS TÉCNICAS. NBR 13555: solo-cimento: determinação da absorção de água : método de ensaio. Rio de Janeiro, 2012e.

ASSOCIAÇÃO BRASILEIRA DE NORMAS TÉCNICAS. NBR 15116: agregados reciclados de resíduos sólidos da construção civil: utilização em pavimentação e preparo de concreto sem função estrutural: requisitos. Rio de Janeiro, 2004.

ASSOCIAÇÃO BRASILEIRA DE NORMAS TÉCNICAS. NBR 15823-2: concreto auto adensável: parte 2: determinação do espalhamento, do tempo de escoamento e do índice de estabilidade visual: método do cone de Abrams. Rio de Janeiro, 2017.

ASSOCIAÇÃO BRASILEIRA DE NORMAS TÉCNICAS. NBR 7211: agregados para concret: especificação. Rio de Janeiro, 2009.

ASSOCIAÇÃO BRASILEIRA DE NORMAS TÉCNICAS. NBR 7681-2: calda de cimento para injeção Parte 2: determinação do índice de fluidez e da vida útil: método de ensaio. Rio de Janeiro, 2013.

ASSOCIAÇÃO BRASILEIRA DE NORMAS TÉCNICAS. NBR 9778: argamassa e concreto endurecidos: determinação da absorção de água, índice de vazios e massa específica. Rio de Janeiro, 2005a.

ASSOCIAÇÃO BRASILEIRA DE NORMAS TÉCNICAS. NBR 9779: argamassa e concreto endurecido: determinação da absorção de água por capilaridade. Rio de Janeiro, 2012a.

BARBOZA, C. S. Avaliação físico-mecânica do solo cimento auto adensável para fabricação de parede monolíticas. Campo Grande, 2014. Dissertação (Mestrado em Eficiência Energética e Sustentabilidade) Universidade Federal do Mato Grosso do Sul, Campo Grande, 2014.

BERTÉ, S. D. D; ALCANTARA, M. A. M. Estudo do comportamento do solo-cimento autoadensável. REEC - Revista Eletrônica de Engenharia Civil, v. 7, n. 2, p. 16-31, 2013.

BERTÉ, S. D. D. Otimização e estudo do comportamento do solo-cimento auto adensável. Ilha Solteira, 2012. Dissertação (Mestrado em Engenharia Civil) - Faculdade de Engenharia, Universidade Estadual Paulista "Júlio de Mesquita Filho", Ilha Solteira, 2012.

BEZERRA, F. T. C.; LAFAYETTE, K. P. V. Avaliação do Resíduo da Construção e Demolição (RCD) em solo-cimento, Revista de Engenharia e Pesquisa Aplicada, v. 2, n. 1, 2016.

CARDOSO, A. A. Desempenho termo físico e mecânico de argamassas de revestimento produzidas com resíduos sólidos poliméricos, minerais e vegetais. Cuiabá, 2017. 152 f. Dissertação (Mestrado em Engenharia de Edificações e Ambiental) - Universidade Federal de Mato Grosso, Cuiabá, 2017.

CLAVERIE, J. Estudo da influência da cinza de casca de arroz e da cal nas propriedades do solocimento autoadensável. Ilha Solteira, 2015. Dissertação (Mestrado em Engenharia Civil) - Faculdade de Engenharia, Universidade Estadual Paulista “Júlio de Mesquita Filho”, Ilha Solteira, 2015.

DELONGUI, L. et al. Panorama dos resíduos da construção civil na região central do Rio Grande do Sul. Teoria e Prática na Engenharia Civil, v. 18, p. 71-80, 2011.

FERNANDES, G. F. Utilização do solo-cimento auto adensável na fabricação de blocos de alvenaria. Ilha Solteira, 2017. Dissertação (Mestrado) - Universidade Estadual Paulista "Júlio de Mesquita Filho", Ilha Solteira, 2017.

FRANÇA, B. R. et al. Durability of soil-cement blocks with the incorporation of limestone residues from the processing of marble. Materials Research, v. 21, supl. 1, p. e20171118, 2018.

FUNDAÇÃO NACIONAL DE SAÚDE. Programas municipais de coleta seletiva de lixo como fator de sustentabilidade dos sistemas públicos de saneamento ambiental na Região Metropolitana de São Paulo. Brasília: Fundação Nacional de Saúde, 2010.

294 Simioni, F. C.; Callekas, I. J. A.; Durante, L. C.; Souza, B. G. de 
GRAF, H. F.; TAVARES, S. F. Energia incorporada dos materiais de uma edificação padrão brasileira residencial. In: CONGRESSO DE INOVAÇÃO, TECNOLOGIA E SUSTENTABILIDADE, 1. Florianópolis, 2010. Anais [...] Florianópolis, 2010.

LLAJARUNA, M. A. V. Estudo do solo-cimento auto adensável para a fabricação de tijolos de pó de mármore e resíduo de construção. Ilha Solteira, 2017. 71 f. Dissertação (Mestrado) - Curso de Curso de Pós-graduação em Engenharia Civil, Universidade Estadual Paulista, Ilha Solteira, 2017.

LU, W.; TAM, V. W. Y. Construction waste management policies and their effectiveness in Hong Kong: a longitudinal review. Renewable and Sustainable Energy Reviews, v. 23, p. 214-223, 2013.

MARTINS, A. P. S. Desenvolvimento, caracterização mecânica e durabilidade de compósitos solocimento autoadensáveis reforçados com fibras de sisal. Rio de Janeiro, 2014. Tese (Doutorado em Engenharia Civil) - Escola de Engenharia, Universidade Federal do Rio de Janeiro, Rio de Janeiro, 2014.

MILANI, A. P. da S.; BARBOZA, C. S. B. Contribuição ao estudo de propriedades do solo cimento autoadensável para fabricação de paredes monolíticas. Ambiente Construído, Porto Alegre, v. 16, n. 4, p. 143-153, out./dez. 2016.

PASSUELLO, A. C. B. et al. Aplicação da avaliação do ciclo de vida na análise de impactos ambientais de materiais de construção inovadores: estudo de caso da pegada de carbono de clínqueres alternativos.

Ambiente Construído, Porto Alegre, v. 14, n. 4, p. 7-20, out./dez. 2014.

REIS, L. R. M. Utilização de resíduos da construção e demolição na fabricação de tijolos de solocimento. Teresina, 2017. 93 f. Dissertação (Mestrado em Engenharia Civil) - Universidade Federal do Piauí. Teresina, 2017.

RIBEIRO, D.; MOURA, L. S.; PIROTE, N. S. S. Sustentabilidade: formas de reaproveitar os resíduos da construção civil. Revista de Ciências Gerenciais, v. 20, n. 31, p. 41-45, 2016.

SAKR, D. A.; SHERIF, A.; EL-HAGGAR, S. M. Environmental management systems' awareness: an investigation of top 50 constractors in Egypt. Journal of cleaner production, v. 18, n. 3, p. 210-218, 2010.

SERVIÇO GEOLÓGICO DO BRASIL. Mapa Geológico do Estado de Mato Grosso. 2004.

SOUZA, B. R.; PAZ, J. G. S.; MILANI, A. P. S. Estudo da viabilidade técnica do solo-cimento auto adensável para fabricação de paredes monolíticas in loco. In: ENCONTRO NACIONAL DE TECNOLOGIA DO AMBIENTE CONSTRUÍDO, 16., São Paulo, 2016. Anais [...] São Paulo, 2016.

SPÓSITO, F. A. et al. Produção de Solo-Cimento Autoadensável utilizando resíduo de PET. Revista Científica ANAP Brasil, v. 11, n. 22, 2018.

VIECILI, M. J. C.; HASTENPFLUG, D.; GIRARDI, R. Comparativo entre o teste de Vicat e a calorimetria semi-adiabática para determinação do tempo de início e fim de pega em cimentos Portland. Revista Matéria, v. 23, n. 3, p. e12172, 2018.

YEHEYIS, M. et al. An overview of construction and demolition waste management in Canada: a life cycle analysis approach to sustainability. Clean Technologies and Environmental Policy, v. 15, p. 81-91, 2013.

\section{Agradecimentos}

À Coordenação de Aperfeiçoamento de Pessoal de Nível Superior (CAPES) e ao Conselho Nacional de Desenvolvimento Científico e Tecnológico $(\mathrm{CNPq})$ pelo financiamento desta pesquisa e ao Instituto Federal de Mato Grosso (IFMT)/ Universidade Federal de Mato Grosso, pela disponibilização dos Laboratórios de Materiais de Construção Civil/ de Materiais. 
Fernanda Cavatti Simioni

Curso de Arquitetura e Urbanismo | Faculdade de Ciências Biomédicas de Cacoal | Av. Cuiabá, 3087, Jardim Clodoaldo | Cacoal - RO Brasil | CEP 76963-665 | Tel.: (69) 3311-1950 | E-mail: nandacavatti@hotmail.com

Ivan Julio Apolonio Callejas

Departamento de Arquitetura e Urbanismo | Universidade Federal de Mato Grosso | Av. Fernando Correa da Costa, 2367, Boa Esperança | Cuiabá - MT - Brasil | CEP 78060-900 | Tel.: (69) 3615-8774 | E-mail: ivancallejas1973@gmail.com

Luciane Cleonice Durante

Departamento de Arquitetura e Urbanismo | Universidade Federal de Mato Grosso | E-mail: luciane.durante@hotmail.com

Bruna Guimarães de Souza

Departamento de Arquitetura e Urbanismo | Universidade Federal de Mato Grosso | E-mail: bruna-guima@outlook.com

\section{Ambiente Construído}

Revista da Associação Nacional de Tecnologia do Ambiente Construído

Av. Osvaldo Aranha, $99-3^{\circ}$ andar, Centro

Porto Alegre - RS - Brasil

CEP 90035-190

Telefone: +55 (51) 3308-4084

Fax: +55 (51) 3308-4054

www.seer.ufrgs.br/ambienteconstruido

E-mail: ambienteconstruido@ufrgs.br

(c) (i) This is an open-access article distributed under the terms of the Creative Commons Attribution License.

296 Simioni, F. C.; Callekas, I. J. A.; Durante, L. C.; Souza, B. G. de 